\title{
ORIGINAL
}

\section{Mental health symptoms in family members of COVID-19 ICU survivors 3 and 12 months after ICU admission: a multicentre prospective cohort study}

Hidde Heesakkers ${ }^{1 *} \mathbb{C}$, Johannes G. van der Hoeven ${ }^{1}$, Stijn Corsten ${ }^{2}$, Inge Janssen ${ }^{3}$, Esther Ewalds ${ }^{4}$, Dominique Burgers-Bonthuis ${ }^{5}$, Thijs C. D. Rettig ${ }^{6}$, Crétien Jacobs $^{7}$, Susanne van Santen ${ }^{8}$, Arjen J. C. Slooter ${ }^{9,10}$, Margaretha C. E. van der Woude ${ }^{11,12}$, Marieke Zegers ${ }^{1}$ and Mark van den Boogaard ${ }^{1 *}$

() 2022 The Author(s)

\begin{abstract}
Purpose: Long-term mental outcomes in family members of coronavirus disease 2019 (COVID-19) intensive care unit (ICU) survivors are unknown. Therefore, we assessed the prevalence of mental health symptoms, including associated risk factors, and quality of life (QoL) in family members of COVID-19 ICU survivors 3 and 12 months post-ICU.

Methods: A prospective multicentre cohort study in ICUs of ten Dutch hospitals, including adult family members of COVID-19 ICU survivors admitted between March 1, and July 1, 2020. Symptom prevalence rates of anxiety, depression (Hospital Anxiety and Depression Scale) and Post-Traumatic Stress Disorder (Impact of Event Scale-6), and QoL (Short Form-12) before ICU admission (baseline), and after 3 and 12 months were measured. Additionally, associations between family and patient characteristics and mental health symptoms were calculated.

Results: A total of 166 out of 197 (84.3\%) included family members completed the 12-month follow-up of whom $46.1 \%$ and $38.3 \%$ had mental health symptoms 3 and 12 months post-ICU, respectively; both higher compared to baseline (22.4\%) ( $p<0.001)$. The mental component summary score of the SF-12 was lower at 12-month follow-up compared with baseline [mean difference mental component score: -5.5 (95\% confidence interval (Cl) - 7.4 to -3.6)]. Furthermore, $27.9 \%$ experienced work-related problems. Symptoms of anxiety (odds ratio (OR) $9.23 ; 95 \% \mathrm{Cl}$ $2.296-37.24 ; p=0.002$ ) and depression (OR 5.96; 95\% Cl 1.29-27.42; $p=0.02$ ) prior to ICU admission were identified as risk factors for mental health symptoms after 12 months.
\end{abstract}

Conclusion: A considerable proportion of family members of COVID-19 survivors reported mental health symptoms 3 and 12 months after ICU admission, disrupting QoL and creating work-related problems.

Keywords: COVID-19, Critical care, Family members, Mental health, Quality of life

*Correspondence: Hidde.heesakkers@radboudumc.nl; Mark.vandenboogaard@radboudumc.nl

${ }^{1}$ Radboud Institute for Health Sciences, Department Intensive Care Medicine, Radboud University Medical Center, P.O. Box 9101, 6500 HB Nijmegen, The Netherlands

Full author information is available at the end of the article

Marieke Zegers and Mark van den Boogaard shared last authorship.

\section{Introduction}

During an intensive care unit (ICU) admission, family members of critically ill patients may experience stressful and uncertain times, affecting their mental health, even on the long term, better known as the Post-Intensive Care Syndrome-Family (PICS-F) [1-3]. These long-term 
mental impairments can result in a decreased quality of life (QoL) and a social and financial burden $[4,5]$.

The prevalence of long-term mental health symptoms in family members of coronavirus disease 2019 (COVID19) ICU survivors is unknown and may be different from the prevalence rate in family members of non-COVID-19 ICU survivors given the circumstances of the pandemic $[6,7]$. The outbreak setting during the first surge of critically ill patients, in which patients were isolated, and the inpatient visiting restrictions resulted in less personal contact and dehumanization of health care [8-10]. Additionally, family members had less contact with clinicians who were taking care for their loved ones, while well-perceived communication and emotional support from clinicians are proven to be important to mitigate PICS-F in non-COVID-19 ICU survivors [7]. Furthermore, the lack of information about prognosis and long-term outcomes was often reported as a stressor by family members of COVID-19 ICU survivors [11, 12].

A better understanding is needed of the impact of a COVID-19 ICU admission on family members to provide adequate support during and after ICU stay [9]. Therefore, the aim of this study was to measure the prevalence of mental health symptoms and QoL in family members of COVID-19 ICU survivors 3 and 12 months after ICU admission, and to explore risk factors associated with mental health symptoms.

\section{Methods}

\section{Study design, setting and population}

This was a prospective multicentre cohort study conducted in ICUs of ten hospitals in the Netherlands (three university, four teaching and three non-teaching hospitals; most participating ICUs were cohort ICUs for the treatment of COVID-19 patients only and since temporary ICUs were created, for instance in the recovery or the paediatric ICU, the exact number of ICUs cannot be reported). The study was approved by the local research ethics committee (CMO region Arnhem-Nijmegen, the Netherlands, number 2020-6878). For the recruitment of family members, 254 COVID-19 ICU patient survivors, who were alive until hospital discharge, of an already established cohort as part of the MONITOR-IC study [13] were approached. These patients were admitted during the first COVID-19 surge in the Netherlands between March 1, 2020 and July 1, 2020 and were enrolled as soon as possible after ICU discharge either before hospital discharge or shortly after. There was no prespecified time point when patients had to be enrolled, but all were included within the first weeks after hospital discharge. After inclusion, the patient was asked for the contact information of the family member most closely involved during the ICU admission, who was approached

\section{Take - home message}

Family members of coronavirus disease 2019 (COVID-19) intensive care unit (ICU) survivors frequently experience mental health symptoms 3 and 12 months after ICU admission, disrupting quality of life and creating work-related problems. ICU treatment for COVID-19 not only has long-term consequences for ICU patients, but also for their families.

subsequently. We excluded survivors and family members who were younger than 16 years. Informed consent was obtained from all ICU survivors and family members.

\section{Data collection}

Family members received questionnaires at three time points: the first questionnaire regarding their perceived mental health before ICU admission (T0) immediately after inclusion and was therefore answered in retrospect, and the second (T1) and third (T2) questionnaire 3 and 12 months after ICU admission, respectively. Questionnaires could be completed on paper or online, depending on the family members' preference. Non-responders received two reminders for all questionnaires.

\section{Outcome measures}

Mental health outcomes were symptoms of anxiety, depression and post-traumatic stress disorder (PTSD). For symptoms of anxiety and depression, the Hospital Anxiety and Depression Scale (HADS) was used, consisting of 14 questions with a 4-point Likert scale (0-3) [14]. The HADS has two 7-question subscales (HADS-Anxiety [HADS-A] and HADS-Depression [HADS-D]) and a cutoff score of $\geq 8$ on each subscale is regarded as indicative for the presence of symptoms of anxiety and depression, respectively.

For symptoms of PTSD, the abbreviated six-item version of the Impact of Event-Revised (IES-R) was used, with a five-point Likert scale (0-4) [15]. The total score was divided by the number of questions resulting in a mean score with a cut-off value of $\geq 1.75$ indicating presence of symptoms of PTSD [16].

QoL was evaluated using the 12-item Short Form Health Survey (SF-12), derived from the SF-36, providing a Physical Component Summary (PCS) and a Mental Component Summary (MCS) score [17]. Both summary scores range from 0 to 100 and a higher score indicates a better perceived QoL. Additionally, work-related problems as result of the ICU admission were assessed by the question: 'Did your work situation change as a direct consequence of the ICU admission of your relative?' [18].

All questionnaires are validated in Dutch, recommended [19] and numerously used in family members 
of COVID-19 and non-COVID-19 ICU survivors [11, 17, 20-22]. Demographics of the family members (e.g. age, education level and relation to the survivor) and ICU experiences (e.g. visiting allowance and the use of an ICU diary) were assessed as well. Additionally, family members were asked if they experienced symptoms of COVID-19 during the ICU admission of their relative and if hospital or ICU admission was required for these symptoms. Demographics of the ICU survivors and ICU admission characteristics, i.e. severity of illness, length of ICU and hospital stay, were retrieved from the NICE (Dutch National Intensive Care Evaluation) registry and medical records [23].

\section{Statistics}

Continuous variables were presented as mean with standard deviation (SD) or median with first and third interquartile range (IQR), depending on their distribution. Categorical variables were presented as proportions. Differences between the prevalence of symptoms at the different time points (T0, T1, T2) were tested using McNemar's test, using the Yates correction for continuity, and presented as proportion with $95 \%$ confidence intervals (CI). A dichotomous composite score for mental health symptoms was calculated to determine the presence of mental health symptoms (anxiety, depression and/or PTSD, as defined above); if at least one symptom of either anxiety, depression or PTSD was present, the composite score was positive. The change in mental symptom and QoL scores between baseline and followup moments were presented as mean or median differences with 95\% CI, using Hodges-Lehmann estimates for the $95 \% \mathrm{CI}$ for the difference between medians, and were tested using the Wilcoxon signed-rank test for the HADS and IES- 6 and the paired $T$ test for the SF-12. A positive median difference for the HADS and IES-6 implies worsening of mental health, whereas a positive mean difference for the SF-12 PCS and MCS implies an improvement in QoL.

Associations between potential risk factors, i.e. baseline characteristics of ICU survivors and family members, ICU admission characteristics and ICU experiences, and the presence of mental health symptoms were analysed using logistic regression analysis and reported as crude odds ratios (ORs) in univariable regression and as adjusted ORs (aOR) in multivariable regression analyses, both with $95 \%$ confidence intervals (CIs). Due to the sample size, not all independent variable could be tested in multivariable analysis and therefore only factors with a $p$ value $<0.20$ in the univariable analysis were included in the multivariable regression analysis [24].

Only family members who completed the baseline and 12-month follow-up questionnaire were included in the analyses. Missing data in the HADS and SF-12 questionnaires were imputed using a subject's means score if at least half of the items were answered (the half-rule). Missing data in the IES- 6 were replaced with the mean score if only one of the six answers was missing $[25,26]$. All statistical tests were two-sided and statistical significance was defined as a $p$ value $<0.05$. Data were analysed using IBM SPSS version 25 (Chicago, IL, USA).

\section{Results \\ Baseline characteristics}

In total, 197 family members consented (77.6\% of 254 eligible survivors and family members), of whom 166 (84.3\%) completed both the baseline and 12-month follow-up questionnaire and were therefore included in the analyses (Fig. 1). Of those, 153 (92.2\%) completed the 3-month follow-up questionnaire.

Family members had a mean age of 57.8 years (SD 11.4) and were mostly female (Table 1 ). ICU survivors had a mean age of 61.1 years (SD 9.3) and were mostly male. Their length of ICU and hospital stay were median 20 days (IQR 11-33) and median 31 days (IQR 21-46), respectively, and $83(50.3 \%)$ survivors were transferred to or from an ICU in another hospital. During follow-up, one survivor died, of whom the family member wished to stop participation and, therefore, no bereaved family members were included in the analyses.

There were no differences in family member, patient and pre-ICU characteristics between responders and non-responders, except for the relationship to the patient as $86.1 \%$ of the responders was a spouse compared to $63 \%$ of the non-responders $(\mathrm{p}=0.01)$ (Supplemental Table S1).

\section{Mental health outcomes}

Before ICU admission and at 3- and 12-month followup, symptoms of anxiety were experienced by $28 / 165$ (17\%), 48/152 (31.6\%) and 47/162 (29\%) family members, respectively, and symptoms of depression by $26 / 165$ (15.8\%), 43/152 (28.3\%) and 37/162 (22.8\%), respectively (Fig. 2 and Supplemental Table S2). Figure 2 shows that the prevalence of symptoms of anxiety and depression was significantly higher at 12-month follow-up compared to baseline, but was the highest at 3-month follow-up. At 3- and 12-month follow-up, symptoms of PTSD were experienced by $45 / 152(29.6 \%)$ and 33/163 (20.2\%) family members, respectively.

Compared with baseline, family members had significantly more mental health symptoms at 3 and 12 months: a positive mental composite score in $22.4 \%$ versus $46.1 \%$ $(p<0.001)$ and $22.4 \%$ versus $38.3 \%(p<0.001)$, respectively. Furthermore, $22.8 \%$ of all family members experienced at least two mental health symptoms (out of 


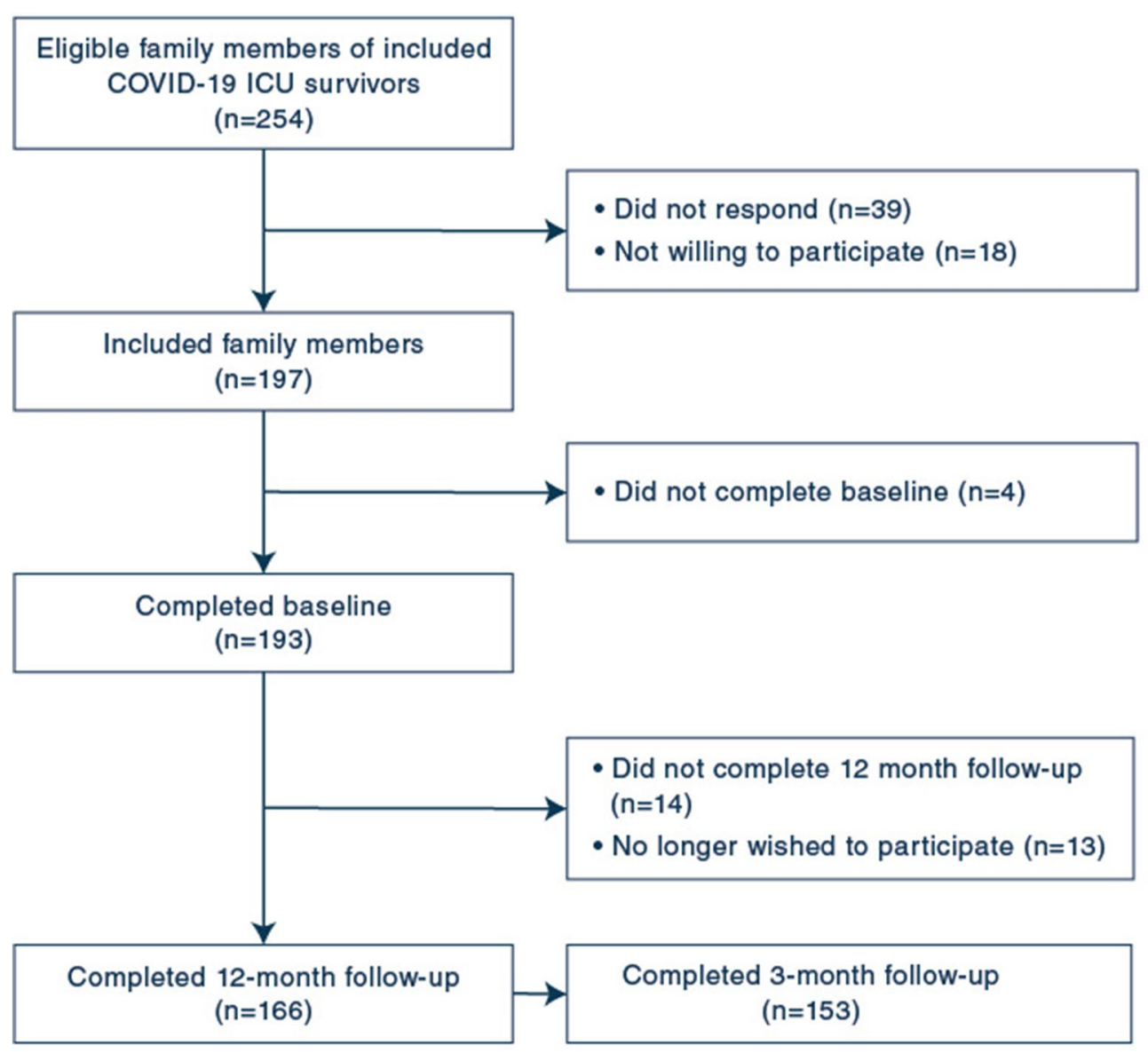

Fig. 1 Enrolment of family members of COVID-19 ICU survivors

anxiety, depression or PTSD) and $11.1 \%$ experienced all three mental health symptoms 12 months after ICU admission (Supplemental Fig. S1). The longitudinal course of mental health symptoms during the first year is depicted in Supplemental Fig. S2, which shows only a small proportion of family members without symptoms at 3 months is experiencing symptoms at 12 months.

Family members had significantly higher scores on the HADS-A and HADS-D at 12-month follow-up than before ICU admission (Table 2). Individual changes in HADS scores from baseline to 12-month follow-up are presented in Supplemental Fig. S3. Additionally, family members' PCS and MCS scores of the SF-12 were significantly lower at 12-month follow-up compared with prior to ICU admission [mean difference scores, PCS: -2.4 (95\% confidence interval (CI) 0.8 to $-4.0, p=0.004$ ) and MCS -5.5 (95\% CI -7.4 to $-3.6, p<0.001)$ ]. A total of 104 family members worked before ICU admission and 12 months after ICU admission 29 (27.9\%) experienced work-related problems $(7 \quad 6.7 \%)$ worked less hours than before ICU admission, 3 (2.9\%) retired early, $8(7.7 \%)$ were still on sick leave and $11(10.6 \%)$ stopped working completely). Mental health symptom scores between 3- and 12-month follow-up show a tendency to decrease, but are not significantly different (Supplemental Table S3).

\section{Risk factors associated with mental health symptoms}

In the multivariable analysis, only symptoms of anxiety or depression before ICU admission were significantly associated with mental health symptoms in family members 12 months after ICU admission with an aOR for symptoms of anxiety of 9.23 (95\% CI 2.29-37.24; $p=0.002$ ) and for symptoms of depression of 5.96 (95\% CI 1.2927.42; $p=0.02$ ) (Table 3 ). In the multivariable analysis for mental health symptoms after 3 months, only symptoms of anxiety before ICU were significantly associated (aOR 6.74; 95\% CI 1.70-26.63); $p=0.007$ ) (Supplemental Table S4). 
Table 1 Baseline characteristics and ICU experiences of family members and ICU survivors

\section{Baseline characteristics}

\begin{tabular}{|c|c|c|}
\hline Age, mean (SD)-years & $57.8(11.4)$ & $61.1(9.3)$ \\
\hline Female sex-n (\%) & $131 / 166(78.9)$ & $41 / 163(25.2)$ \\
\hline \multicolumn{3}{|l|}{ Relationship to survivor $-n(\%)$} \\
\hline Patient is my spouse & 143/166 (86.1) & \\
\hline Patient is my parent & $15 / 166(9)$ & \\
\hline Other (i.e. child or sibling) & $8 / 166(4.8)$ & \\
\hline High education level—n(\%) & $47 / 163(28.8)$ & \\
\hline Symptoms of COVID-19 during ICU admission of survivor-yes, $n(\%)$ & $88 / 161(54.7)$ & \\
\hline APACHE IV score, mean (SD) ${ }^{b}$ & & $59.6(17.9)$ \\
\hline Length of ICU stay, median [IQR]—-days & & $20[11-33]$ \\
\hline Length of hospital stay, median [IQR]_-days & & $31(21-46)$ \\
\hline Chronic disease, yes, $n(\%)$ & & $36 / 164(22)$ \\
\hline \multicolumn{3}{|l|}{ ICU experiences } \\
\hline Physical visitation allowed-n (\%) & $N=165$ & \\
\hline Never & $77(46.7)$ & \\
\hline One to six times a week & $45(27.3)$ & \\
\hline Every day & $43(26.1)$ & \\
\hline Non-physical contact (e.g. by phone or video call) — n (\%) & $N=165$ & \\
\hline Never & $57(34.5)$ & \\
\hline One to six times a week & $56(33.9)$ & \\
\hline Every day & $52(31.3)$ & \\
\hline Patient was transferred to or from another hospital-yes, $n$ (\%) & $83 / 165(50.3)$ & \\
\hline Use of ICU diary during ICU stay-yes, $n(\%)$ & 106/164 (64.6) & \\
\hline
\end{tabular}

\section{Discussion}

This multicentre prospective cohort study showed that a substantial part of family members of COVID-19 ICU survivors experienced mental health symptoms 12 months after ICU admission: $38.3 \%$ experienced at least one mental health symptom (anxiety, depression or PTSD) and $22.8 \%$ experienced two or more mental health symptoms. The prevalence rates of mental health symptoms tended to decrease non-significantly from 3 to 12 months post-ICU, which has also been reported in family members of non-COVID-19 ICU patients, but were significantly higher at both follow-up moments compared to pre-ICU [2]. Twelve months after ICU admission, the mental component QoL summary score was significantly reduced with 5.5 points, which is higher than the minimal clinically important difference of 5 points [27]. In addition, over one out of four family members experienced work-related problems due to the ICU admission of their relative. The risk for mental health symptoms 12 months after ICU admission was over five times higher for family members with pre-ICU mental health symptoms.

Reported HADS scores at 3-month follow-up in a comparable study in family members of COVID-19 ICU patients seem somewhat lower compared with our results (HADS-A: median 3 [IQR 2-7] versus median 5 [IQR 2-8] and HADS-D: median 2 [IQR 1-6] versus median 3 [IQR 0.5-8]) [22]. However, this single centre study, included less family members of COVID-19 ICU survivors $(N=78)$ and did not report the prevalence of mental health symptoms before ICU admission, which is strongly associated with long-term outcomes, and therefore important for the interpretation of the results.

Currently, there are no other studies reporting 12-month mental outcomes of family members of COVID-19 ICU patients, meaning our 12-month outcomes can only be compared with studies including family members of non-COVID-19 ICU patients. One study using the IES-R, from which the IES-6 is derived, found symptoms of PTSD in $80 \%$ at 12-month follow-up 


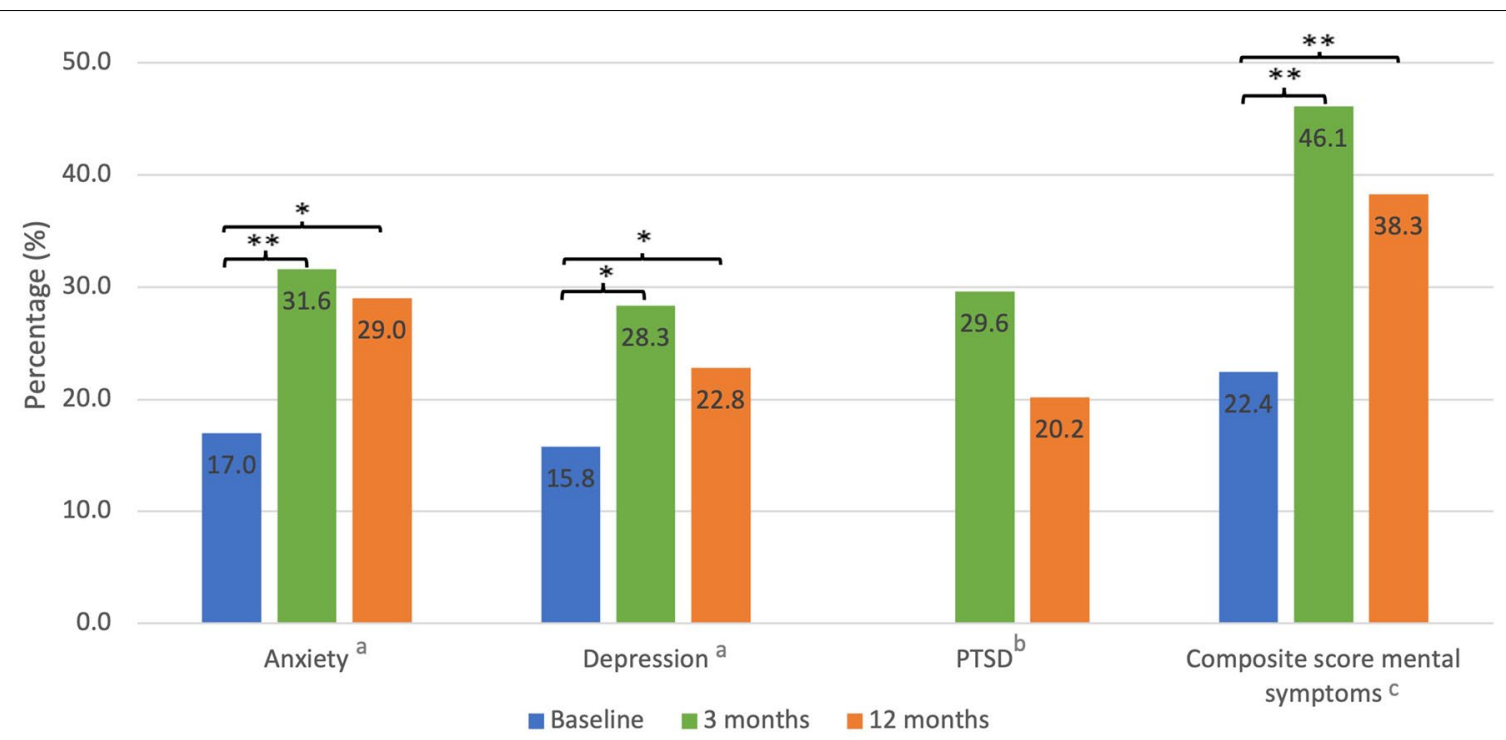

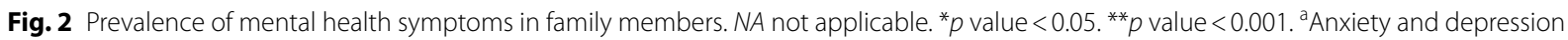
symptoms were defined by a score of $\geq 8$ on the Hospital Anxiety and Depression Scale (HADS). ${ }^{b}$ Symptoms of Post-traumatic stress disorder (PTSD) were defined by a mean of all questions $\geq 1.75$ on the IES-6. Baseline data is not applicable. 'Composite score for mental: one or more mental health symptoms (Anxiety, depression, PTSD) present

Table 2 Mental health outcomes and quality of life in family members

\begin{tabular}{|c|c|c|c|c|c|}
\hline & T0, $N=166$ & $\mathrm{~T} 1, N=153$ & $\mathrm{~T} 2, N=166$ & Difference $(95 \% \mathrm{Cl})$ T0 vs. T2 & $p$ value \\
\hline HADS-anxiety, ${ }^{a}$ Median [IQR] & $3[1-6]$ & $5[2-8]$ & $4.5[2-8]$ & $1[0.5$ to 1.5$]$ & $<0.001$ \\
\hline HADS-depression, ${ }^{a}$ Median [IQR] & $1[0-5]$ & $3[0.5-8]$ & $3[0-7]$ & $1[0.5$ to 1.5$]$ & $<0.001$ \\
\hline IES-6, Median [IQR] & N.A & $0.8[0.3-2]$ & $1[0.3-1.5]$ & N.A & N.A \\
\hline SF-12 PCS, ${ }^{C}$ Mean (SD) & $54.2(8.9)$ & $51.3(11.2)$ & $51.9(10.9)$ & $-2.4(0.8$ to -4$)$ & 0.004 \\
\hline SF-12 MCS, ${ }^{\mathrm{C}}$ Mean (SD) & $51.6(8.9)$ & $41.3(12.9)$ & $46.1(11)$ & $-5.5(-7.4$ to -3.6$)$ & $<0.001$ \\
\hline
\end{tabular}

Differences in HADS and IES-6 scores are presented as median differences and SF-12 scores as mean differences. Differences are based on complete cases

$S D$ standard deviation, IQR interquartile range, $C l$ confidence interval, T0 baseline measurement, T1 3-month follow-up, T2 12-month follow-up

a Hospital Anxiety and Depression scale

b Impact of events scale-6

c 12-item Short Form Health Survey, physical and mental component score (PCS and MSC, respectively)

[28]. However, this study also included family members of non-survivors and used a lower cut-off value, which likely explains the higher prevalence of symptoms compared with our results [20]. Two other studies in family members of non-COVID-19 ICU survivors reported prevalence rates of depression at 12-month follow-up of $22.8 \%$ [5], similar to our results, and 43\% [29]. However, both used a different questionnaire, namely the Center for Epidemiologic Depression Scale (CES-D), and therefore, results cannot be compared directly. Unfortunately, there are no available studies reporting 12-month outcomes in family members of ICU patients using the HADS, even though the HADS is recommend for studies in ICU patients and their family members $[19,30]$. A study in family members of non-COVID-19 ICU patients did found comparable QoL scores at 3- and 12-month follow-up [31].

The lack of studies makes it difficult to compare mental outcomes between our study and long-term studies in family members of non-COVID-19 ICU survivors. However, the experience of the ICU admission will be different for family members of COVID-19 patients due to the pandemic and disease characteristics [7]. Since prolonged exposure to an infected person contributes to a higher risk of infection, many family members will have had COVID-19 themselves, as was underlined by our results $(54.7 \%$ of the family members experienced symptoms of COVID-19) [32]. There is growing evidence that 
Table 3 Risk factors for one or more mental health symptoms in family members $\mathbf{1 2}$ months after ICU admission

\begin{tabular}{|c|c|c|c|c|}
\hline & \multicolumn{4}{|l|}{ Mental health symptoms ${ }^{a}$} \\
\hline & Univariable OR $(95 \% \mathrm{Cl})$ & p value & Multivariable OR $(95 \% \mathrm{Cl})$ & $p$ value \\
\hline \multicolumn{5}{|l|}{ Family } \\
\hline Age & $1.01(0.98-1.04)$ & 0.68 & & \\
\hline Female sex & $1.86(0.8-4.32)$ & 0.15 & $2.52(0.81-7.81)$ & 0.11 \\
\hline \multicolumn{5}{|l|}{ Relationship to survivors } \\
\hline Spouse & - & & & \\
\hline Parent & $0.77(0.25-2.38)$ & 0.65 & & \\
\hline Other & $0.62(0.12-3.3)$ & 0.57 & & \\
\hline Education level, high b & $0.88(0.43-1.8)$ & 0.72 & & \\
\hline \multicolumn{5}{|l|}{ Pre-ICU health status } \\
\hline Anxiety symptoms ${ }^{c}$ & $20.21(5.74-71.08)$ & $<0.001$ & $9.23(2.29-37.24)$ & 0.002 \\
\hline Depression symptoms $^{c}$ & $17.6(4.99-62.14)$ & $<0.001$ & $5.96(1.29-27.42)$ & 0.02 \\
\hline \multicolumn{5}{|l|}{ ICU experience } \\
\hline Physical visitation allowed, Never & $0.95(0.5-1.8)$ & 0.87 & & \\
\hline Non-physical contact, Never & $0.8(0.41-1.56)$ & 0.51 & & \\
\hline Transferred to/from another ICU, Yes & $0.59(0.31-1.12)$ & 0.11 & $0.83(0.36-1.92)$ & 0.65 \\
\hline $\begin{array}{l}\text { Symptoms of COVID-19 during ICU admission of } \\
\text { ICU survivor, yes }\end{array}$ & $1.17(0.61-2.22)$ & 0.74 & & \\
\hline Use of ICU diary & $0.49(0.25-0.96)$ & 0.04 & $0.58(0.24-1.42)$ & 0.23 \\
\hline \multicolumn{5}{|l|}{ ICU survivor } \\
\hline Age & $1(0.97-1.04)$ & 0.87 & & \\
\hline Female sex & $1.04(0.5-2.19)$ & 0.91 & & \\
\hline APACHE IV score ${ }^{d}$ & $1.01(0.99-1.03)$ & 0.33 & & \\
\hline Length of ICU stay & $1(0.98-1.02)$ & 0.8 & & \\
\hline Length of hospital stay & $1(0.99-1.02)$ & 0.52 & & \\
\hline Symptoms of anxiety at 12 months & $2.45(1.01-5.94)$ & 0.05 & $2.76(0.86-8.83)$ & 0.09 \\
\hline Symptoms of depression at 12 months & $1.67(0.71-3.94)$ & 0.24 & & \\
\hline Symptoms of PTSD at 12 months & $2.97(0.99-8.85)$ & 0.05 & $2.04(0.49-8.46)$ & 0.34 \\
\hline
\end{tabular}

a SARS-CoV-2 infection, even without hospital admission, can lead to long-term mental health symptoms, i.e. long COVID [33]. Quarantine, isolation and social distancing because of the SARS-CoV-2 infection of the patient might also contributes to the worsening of mental health of family members [34]. Additionally, the impaired work status of family members might not only be due to the impact of the ICU admission of a relative but potentially caused by the consequences of a COVID-19 as well.

In family members of non-COVID-19 ICU patients, female sex, younger age and being a child of a patient were frequently associated with symptoms of anxiety, depression and PTSD [3, 35], but not in the present study. However, in none of these studies, pre-ICU mental health was corrected for as potential confounder, a strong risk factor for mental health symptoms 12 months after ICU admission in our results. Only one study in family members of non-COVID-19 explored pre-ICU symptoms of anxiety and depression and found a significant association with 2-month follow-up symptoms of PTSD [36].

To prevent or mitigate long-term mental health symptoms, family support teams with fixed contact persons could be used to provide family members of COVID19 ICU patients with frequent updates when visitation is restricted [37]. Additionally, family members need proper information, e.g. about the trajectory of mental health symptoms [12]. The present study provides clinicians with this information, enabling them to better inform COVID-19 survivors and family members. Furthermore, our findings emphasize clinicians should be 
aware of long-term mental health symptoms, not only in COVID-19 ICU survivors, but also in their family members. Family members at risk for long-term mental symptoms can be identified by the presence of mental health symptoms prior to ICU admission. Those family members could be screened for mental health symptoms at a post-ICU clinic by ICU clinicians or by a general practitioner or community nurse and referred to a specialised healthcare professional, e.g. a clinical psychologist, when symptoms are present [19].

\section{Strength and limitations of this study}

This study has several limitations. First, only family members of ICU survivors were included, so no conclusion can be drawn regarding bereaved family members. Bereaved family members of non-COVID-19 ICU patients experience more mental health symptoms than family members of non-COVID-19 ICU survivors [38]. Additionally, family members who did not say goodbye or witnessed terminal dyspnoea experienced more symptoms as well. Therefore, it is likely the prevalence of mental health symptoms in bereaved family members of COVID-19 ICU patients is higher compared with our results [39]. Second, there was no control group of non-COVID-19 ICU family members to compare our outcomes with. Therefore, outcomes of this study were compared with previous studies. Third, due to the unplanned ICU admission, information regarding baseline mental health was assed retrospectively, potentially causing recall bias. However, this information is vital for the interpretation of long-term outcomes. Fourth, we only studied the mental health symptoms, while nonCOVID-19 ICU studies suggest that family members may experience physical and cognitive symptoms as well [40]. Additionally, we had no information regarding the type of ICU, e.g. a traditional, a cohort ICU for COVID-19 patients only, or extra created ICUs (e.g. originally recovery or paediatrics unit) or medical comorbidities, e.g. respiratory or cardiovascular insufficiencies, of the family members, which could have impacted the development of mental health symptoms [41]. Fifth, although statistically significant, factors associated with mental health outcomes (pre-ICU mental health) have broad CIs. Therefore, the results of this exploratory study should be confirmed with larger sample sizes.

\section{Conclusion}

Critical illness due to COVID-19 not only has long-term consequences for ICU patients, but also for their family members. At 3 and 12 months after ICU admission, the prevalence of mental health symptoms in family members of COVID-19 ICU survivors is significantly higher compared with pre-ICU. Additionally, family members experienced a reduction of QoL and an impaired work status. Clinicians, including non-ICU clinicians (e.g. general practitioners) should be aware of high prevalence of mental health problems among family member of COVID-19 ICU patients, especially in family members with mental health symptoms prior to ICU admission. Future research should focus on developing effective strategies to prevent long-term mental health symptoms in family members of COVID-19 ICU survivors.

Supplementary Information

The online version contains supplementary material available at https://doi. org/10.1007/s00134-021-06615-8.

\section{Author details}

${ }^{1}$ Radboud Institute for Health Sciences, Department Intensive Care Medicine, Radboud University Medical Center, P.O. Box 9101, 6500 HB Nijmegen, The Netherlands. ${ }^{2}$ Department of Intensive Care Medicine, Canisius Wilhelmina Hospital, Nijmegen, The Netherlands. ${ }^{3}$ Department of Intensive Care Medicine, Maasziekenhuis Pantein, Beugen, The Netherlands. ${ }^{4}$ Department of Intensive Care Medicine, Bernhoven Hospital, Uden, The Netherlands. ${ }^{5}$ Department of Intensive Care Medicine, Rijnstate Hospital, Arnhem, The Netherlands. ${ }^{6}$ Department of Anesthesiology, Intensive Care and Pain Medicine, Amphia Hospital, Breda, The Netherlands. ${ }^{7}$ Department of Intensive Care Medicine, Elkerliek Hospital, Helmond, The Netherlands. ${ }^{8}$ Department of Intensive Care Medicine, Maastricht University Medical Center, Maastricht, The Netherlands. ${ }^{9}$ Department of Intensive Care Medicine and UMC Utrecht Brain Center, University Medical Center Utrecht, Utrecht University, Utrecht, The Netherlands. ${ }^{10}$ Department of Neurology, UZ Brussel and Vrije Universiteit Brussel, Brussels, Belgium. ${ }^{11}$ Department of Intensive Care, Heerlen Medical Center, Heerlen, The Netherlands. ${ }^{12}$ Department of Quality and Safety, Heerlen Medical Center, Heerlen, The Netherlands.

\section{Acknowledgements}

We would like to express our gratitude to all patients and family members for their participation. In addition, we are grateful for the contributions of the ICU staff of all participating hospitals.

\section{Author contributions}

$\mathrm{HH}, \mathrm{MvdB}$ and $\mathrm{MZ}$ had full access to all of the data in the study and take responsibility for the integrity of the data and the accuracy of the data analysis. $H H, J G v d H, M v d B, M Z$ contributed to study concept and design. $\mathrm{HH}$, JGvdH, SC, IJ, EE, DB-B, TCDR, CJ, SvS, AJCS, MCEvdW, MvdB, MZ contributed to acquisition and interpretation of the data. $\mathrm{HH}, \mathrm{MZ}, \mathrm{MvdB}$ contributed to analysis and interpretation of data. $\mathrm{HH}$ contributed to drafting of the article. JGvdH, SC, IJ, EE, DB-B, TCDR, CJ, SvS, AJCS, MCEvdW, MvdB, MZ contributed to critical revision of the article for important intellectual content. MvdB, MZ both supervised the study. The corresponding author attests that all listed authors meet the ICMJE authorship criteria and that no others meeting the criteria have been omitted.

Funding

No funding or financial support was received.

\section{Availability of data and materials}

The datasets used and/or analysed during the current study are available from the corresponding author on reasonable request.

Code availability

Not applicable.

Declarations

Conflicts of interest

All authors declare no conflict of interest. 


\section{Ethical approval}

The study was approved by the medical ethical committee of ArnhemNijmegen, the Netherlands (CMO) (CMO-number: 2020-6878).

\section{Consent to participate}

Informed consent was obtained from all participating ICU survivors and family members.

\section{Consent for publication}

Not applicable.

\section{Open Access}

This article is licensed under a Creative Commons Attribution-NonCommercial 4.0 International License, which permits any non-commercial use, sharing, adaptation, distribution and reproduction in any medium or format, as long as you give appropriate credit to the original author(s) and the source, provide a link to the Creative Commons licence, and indicate if changes were made. The images or other third party material in this article are included in the article's Creative Commons licence, unless indicated otherwise in a credit line to the material. If material is not included in the article's Creative Commons licence and your intended use is not permitted by statutory regulation or exceeds the permitted use, you will need to obtain permission directly from the copyright holder. To view a copy of this licence, visit http://creativecommons.org/licen ses/by-nc/4.0/

\section{Publisher's Note}

Springer Nature remains neutral with regard to jurisdictional claims in published maps and institutional affiliations.

Received: 22 September 2021 Accepted: 27 December 2021 Published online: 1 February 2022

\section{References}

1. Needham DM, Davidson J, Cohen H et al (2012) Improving long-term outcomes after discharge from intensive care unit: report from a stakeholders' conference. Crit Care Med 40:502-509. https://doi.org/10. 1097/CCM.0b013e318232da75

2. Haines KJ, Denehy L, Skinner EH et al (2015) Psychosocial outcomes in informal caregivers of the critically ill: a systematic review. Crit Care Med 43:1112-1120. https://doi.org/10.1097/ccm.0000000000000865

3. Johnson CC, Suchyta MR, Darowski ES et al (2019) Psychological sequelae in family caregivers of critically iii intensive care unit patients. A systematic review. Ann Am Thorac Soc 16:894-909. https://doi.org/10.1513/ AnnalsATS.201808-540SR

4. Wintermann GB, Weidner K, Strauß B et al (2016) Predictors of posttraumatic stress and quality of life in family members of chronically critically ill patients after intensive care. Ann Intensive Care 6:69. https://doi.org/10. 1186/s13613-016-0174-0

5. Van Pelt DC, Milbrandt EB, Qin L et al (2007) Informal caregiver burden among survivors of prolonged mechanical ventilation. Am J Respir Crit Care Med 175:167-173. https://doi.org/10.1164/rccm.200604-493OC

6. Feder S, Smith D, Griffin H et al (2020) "Why couldn't I go in to see him?" bereaved families' perceptions of end-of-life communication during COVID-19. J Am Geriatr Soc. https://doi.org/10.1111/jgs.16993

7. Azoulay É, Curtis JR, Kentish-Barnes N (2021) Ten reasons for focusing on the care we provide for family members of critically ill patients with COVID-19. Intensive Care Med 47:230-233. https://doi.org/10.1007/ s00134-020-06319-5

8. Nadig NR, Sterba KR, Simpson AN et al (2021) Psychological outcomes in family members of acute respiratory failure patients: does inter-ICU transfer play a role? Chest. https://doi.org/10.1016/j.chest.2021.03.025

9. Parotto M, Myatra SN, Munblit D et al (2021) Recovery after prolonged ICU treatment in patients with COVID-19. Lancet Respir Med. https://doi. org/10.1016/s2213-2600(21)00318-0

10. Rodriguez-Ruiz E, Campelo-Izquierdo M, Estany-Gestal A et al (2021) Impact of different visiting policies on family satisfaction in two Spanish ICUs before and during COVID-19. Intensive Care Med 47:1165-1166. https://doi.org/10.1007/s00134-021-06485-0
11. Zante B, Camenisch SA, Schefold JC (2020) Interventions in post-intensive care syndrome-family: a systematic literature review. Crit Care Med 48:e835-e840. https://doi.org/10.1097/ccm.0000000000004450

12. Rahimi T, Dastyar N, Rafati F (2021) Experiences of family caregivers of patients with COVID-19. BMC Fam Pract 22:137. https://doi.org/10.1186/ s12875-021-01489-7

13. Geense W, Zegers M, Vermeulen H et al (2017) MONITOR-IC study, a mixed methods prospective multicentre controlled cohort study assessing 5-year outcomes of ICU survivors and related healthcare costs: a study protocol. BMJ Open 7:e018006. https://doi.org/10.1136/bmjop en-2017-018006

14. Zigmond AS, Snaith RP (1983) The hospital anxiety and depression scale. Acta Psychiatr Scand 67:361-370. https://doi.org/10.1111/j.1600-0447. 1983.tb09716.x

15. Thoresen S, Tambs K, Hussain A et al (2010) Brief measure of posttraumatic stress reactions: Impact of Event Scale-6. Soc Psychiatry Psychiatr Epidemiol 45:405-412. https://doi.org/10.1007/s00127-009-0073-x

16. Hosey MM, Leoutsakos JS, Li X et al (2019) Screening for posttraumatic stress disorder in ARDS survivors: validation of the Impact of Event Scale-6 (IES-6). Crit Care 23:276. https://doi.org/10.1186/ s13054-019-2553-Z

17. Ware J Jr, Kosinski M, Keller SD (1996) A 12-Item Short-Form Health Survey: construction of scales and preliminary tests of reliability and validity. Med Care 34:220-233. https://doi.org/10.1097/00005650-19960 3000-00003

18. Griffiths J, Hatch RA, Bishop J et al (2013) An exploration of social and economic outcome and associated health-related quality of life after critical illness in general intensive care unit survivors: a 12-month follow-up study. Crit Care 17:R100. https://doi.org/10.1186/cc12745

19. van Beusekom I, Bakhshi-Raiez F, de Keizer NF et al (2016) Reported burden on informal caregivers of ICU survivors: a literature review. Crit Care 20:16. https://doi.org/10.1186/s13054-016-1185-9

20. Azoulay E, Pochard F, Kentish-Barnes N et al (2005) Risk of post-traumatic stress symptoms in family members of intensive care unit patients. Am J Respir Crit Care Med 171:987-994. https://doi.org/10.1164/rccm. 200409-12950C

21. Jones C, Skirrow P, Griffiths RD et al (2004) Post-traumatic stress disorderrelated symptoms in relatives of patients following intensive care. Intensive Care Med 30:456-460. https://doi.org/10.1007/s00134-003-2149-5

22. van Veenendaal N, van der Meulen IC, Onrust M et al (2021) Six-month outcomes in COVID-19 ICU patients and their family members: a prospective cohort study. Healthcare (Basel). https://doi.org/10.3390/healt hcare9070865

23. NICE www.stichting-nice.nl. In: Editor (ed) Book www.stichting-nice.nl. City

24. Maldonado G, Greenland S (1993) Simulation study of confounder-selection strategies. Am J Epidemiol 138:923-936. https://doi.org/10.1093/ oxfordjournals.aje.a116813

25. Ware JE, Kosinksi M, Gandek B (2005.) SF-36 health survey: manual and interpretion guide. The Health Institute, New England Medical Center, Boston

26. Bell ML, Fairclough DL, Fiero MH et al (2016) Handling missing items in the Hospital Anxiety and Depression Scale (HADS): a simulation study. BMC Res Notes 9:479. https://doi.org/10.1186/s13104-016-2284-z

27. Dowdy DW, Eid MP, Sedrakyan A et al (2005) Quality of life in adult survivors of critical illness: a systematic review of the literature. Intensive Care Med 31:611-620. https://doi.org/10.1007/s00134-005-2592-6

28. Garrouste-Orgeas M, Coquet I, Périer A et al (2012) Impact of an intensive care unit diary on psychological distress in patients and relatives* ${ }^{*}$ Crit Care Med 40:2033-2040. https://doi.org/10.1097/CCM.0b013e3182 $4 \mathrm{e} 1 \mathrm{~b} 43$

29. Cameron Jl, Chu LM, Matte A et al (2016) One-year outcomes in caregivers of critically ill patients. N Engl J Med 374:1831-1841. https://doi.org/ 10.1056/NEJMoa1511160

30. Needham DM, Sepulveda KA, Dinglas VD et al (2017) Core outcome measures for clinical research in acute respiratory failure survivors. An international modified Delphi consensus study. Am J Respir Crit Care Med 196:1122-1130. https://doi.org/10.1164/rccm.201702-03720C

31. Alfheim HB, Småstuen MC, Hofsø K et al (2019) Quality of life in family caregivers of patients in the intensive care unit: a longitudinal study. Aust Crit Care 32:479-485. https://doi.org/10.1016/j.aucc.2018.09.005 
32. Wiersinga WJ, Rhodes A, Cheng AC et al (2020) Pathophysiology, transmission, diagnosis, and treatment of coronavirus disease 2019 (COVID19): a review. JAMA 324:782-793. https://doi.org/10.1001/jama.2020. 12839

33. Crook H, Raza S, Nowell J et al (2021) Long COVID-mechanisms, risk factors, and management. BMJ 374:n1648. https://doi.org/10.1136/bmj. n1648

34. Brooks SK, Webster RK, Smith LE et al (2020) The psychological impact of quarantine and how to reduce it: rapid review of the evidence. Lancet 395:912-920. https://doi.org/10.1016/s0140-6736(20)30460-8

35. Choi J, Sherwood PR, Schulz R et al (2012) Patterns of depressive symptoms in caregivers of mechanically ventilated critically ill adults from intensive care unit admission to 2 months postintensive care unit discharge: a pilot study. Crit Care Med 40:1546-1553. https://doi.org/10. 1097/CCM.0b013e3182451c58

36. Andresen M, Guic E, Orellana A et al (2015) Posttraumatic stress disorder symptoms in close relatives of intensive care unit patients: prevalence data resemble that of earthquake survivors in Chile. J Crit Care 30:1152. e1157-1111. https://doi.org/10.1016/j.jcrc.2015.06.009
37. Klop HT, Nasori M, Klinge TW et al (2021) Family support on intensive care units during the COVID-19 pandemic: a qualitative evaluation study into experiences of relatives. BMC Health Serv Res 21:1060. https://doi.org/10. 1186/s12913-021-07095-8

38. Schmidt M, Azoulay E (2012) Having a loved one in the ICU: the forgotten family. Curr Opin Crit Care 18:540-547. https://doi.org/10.1097/MCC. ob013e328357f141

39. Kentish-Barnes N, Cohen-Solal Z, Morin L et al (2021) Lived experiences of family members of patients with severe COVID-19 who died in intensive care units in France. JAMA Netw Open 4:e2113355. https://doi.org/10. 1001/jamanetworkopen.2021.13355

40. Douglas SL, Daly BJ (2003) Caregivers of long-term ventilator patients: physical and psychological outcomes. Chest 123:1073-1081. https://doi. org/10.1378/chest.123.4.1073

41. Druss B, Walker E, (2011) Mental disorders and medical comorbidity. The synthesis project research synthesis report 1-26 